\title{
Platelet-Rich Plasma in the Treatment of Hair Disorders
}

\author{
Antonella Tosti $^{\mathrm{a}} \quad$ Dimitris Rigopoulos $^{\mathrm{b}}$ \\ ${ }^{a}$ Department of Dermatology, University of Miami, Miami, FL, USA; ${ }^{b}$ National and Kapodistrian University of Athens, \\ Athens, Greece
}

Platelet-rich plasma (PRP) is highly required by patients with hair loss and is becoming increasingly popular for the treatment of hair disorders worldwide.

It is therefore important for dermatologists interested in hair disorders to be ready to answer all the questions their patients will ask regarding the mechanism of action as well as the efficacy and safety of this procedure.

This issue of Skin Appendage Disorders contains two review articles focused on PRP. One review is more fo- cused on efficacy, with a critical evaluation of the clinical studies that have been published so far, and the other is focused on the modality of preparations and the mechanism of action.

We hope that our readers will utilize these very comprehensive reviews to improve their skills on PRP if they are already performing the procedure or to start considering utilizing PRP in their clinical practice.

\section{KARGER}

(C) 2017 S. Karger AG, Basel

E-Mail karger@karger.com

www.karger.com/sad
Antonella Tosti

Department of Dermatology, University of Miami

1295 NW 14th Street, Suite K

Miami, FL 33125 (USA)

E-Mail atosti@ med.miami.edu 